\title{
Hand hygiene skills of the health care workers and the effect of training and educational intervention: $A$ single center cross-sectional study
}

Gentle Sunder Shrestha*1, Manjit Shrestha ${ }^{2}$, Roshan Sharma ${ }^{2}$, Ramchandra KC ${ }^{3}$, Bibeka Shrestha ${ }^{4}$, Rojika Pradhan ${ }^{5}$, Pankaj Joshi ${ }^{6}$

DOI: https://doi.org/10.3329/bccj.v9i1.53050

\begin{abstract}
:
Background: Hand hygiene is one of the most effective preventive measures in the transmission of infection. Proper hand hygiene strategies in health care facilities can reduce nosocomial infections and antimicrobial resistance.

Objectives: This study aims to assess the baseline hand hygiene skills among health care workers and the impact of education and training on it.

Design: Interventional cross-sectional single center study.

Method: It was conducted among 181 health care workers of Alka Hospital Pvt. Ltd. During both pre and post-test, participants were asked to perform hand hygiene with soap and water as per WHO guidelines. Pretest was conducted to assess baseline skills of health care workers regarding hand hygiene. An observer would score whether each of the steps were performed correctly, using a checklist. It was followed by intervention in the form of training, education and demonstration of hand hygiene. Post-test was conducted to assess the changes in skills after intervention.

Results: There was an overall improvement in the hand washing skills post intervention indicated by an increase in median score, which was 8 for pre-intervention and 9 for post-intervention. Doctors and nurses had better practice regarding hand hygiene in comparison to other participants. Those participants who had prior training on infection prevention and control, were found to have better hand hygiene skills post-intervention.
\end{abstract}

Conclusion: Training and educational interventions are the effective tools to improve hand hygiene skills of the health care workers. Performing such interventions at regular intervals can be helpful.

Keywords: hand hygiene, health care workers, training and education.

\section{Introduction:}

Hand washing is one of the most effective preventive measures in the transmission of communicable diseases or

1. Associate Professor, Department of Anaesthesiology, Tribhuvan University Teaching Hospital, Maharajgunj, Kathmandu, Nepal

2. Consultant Intensivist, Intensive Care Unit, Alka Hospital Pvt. Ltd, Jawalakhel, Lalitpur, Nepal

3. Medical Officer, Intensive Care Unit, Alka Hospital Pvt. Ltd, Jawalakhel, Lalitpur, Nepal

4. Kathmandu Medical College, Sinamangal, Kathmandu, Nepal

5. Chief of Administration, Alka Hospital Pvt. Ltd, Jawalakhel, Lalitpur, Nepal

6. Assistant Professor, Department of Anaesthesiology, Tribhuvan University Teaching Hospital, Maharajgunj, Kathmandu, Nepal

*Corresponding Author:

Dr. Gentle Sunder Shrestha MD, FACC, EDIC, FCCP, FNCS

Associate Professor, Department of Anaesthesiology

Tribhuvan University Teaching Hospital

Maharajgunj, Kathmandu, Nepal

Email: gentlesunder@hotmail.com

Phone: +977-9841248584 infection. Scientific evidence from World Health Organization (WHO) has shown that improving hand hygiene strategies in health care facilities can reduce nosocomial infections and antimicrobial resistance. ${ }^{1}$ According to WHO, approximately $70 \%$ of health care workers do not practice health hygiene, with health workers reporting misunderstandings about the relevance and importance of hand hygiene in everyday clinical practice. ${ }^{2}$ With the lack of adequate knowledge and improvement programs in hand hygiene, health care workers compliance with hand hygiene best practices can be as low as eight percent. ${ }^{3}$ Effective hand hygiene techniques include application of adequate amount of health hygiene agents, adequate duration of hand hygiene, coverage of all hand surfaces and adequate time spent for hand drying. ${ }^{4} \mathrm{~A}$ fundamental shift in the change in behavior, attitude and practices of health care workers can save many lives by preventing the transmission.

This study aims to assess the baseline status of appropriateness of hand washing technique among health care workers in a single center and the impact of education and training on it.

\section{Material and Methods:}

This was an interventional cross-sectional study of hand 
hygiene performed on June 14 to 17, 2020. It was conducted among the health care workers including doctors, nurses, health assistants, ward helpers and all other staffs of Alka Hospital Pvt. Ltd, Jawalakhel, Lalitpur. It consisted of pre and post-test with the same checklist. The pretest was conducted to assess baseline skills of health care workers regarding hand hygiene. During both pre and post-test, participants were asked to perform hand hygiene with soap and water as per WHO guidelines. An observer would score whether each of the steps were performed correctly, using a checklist, that consisted of 11 steps. It was followed by training and educational intervention, which was in the form of a 30 minutes lecture about infection prevention and hand hygiene, and then by a live demonstration of all steps of hand hygiene, as recommended by WHO. After that, post-test was conducted to assess the changes in skills after intervention. The tests and classes were conducted over the duration of two hours. The checklist was prepared in accordance with WHO hand hygiene guidelines. ${ }^{4}$

Sample size was calculated by using formula $\mathrm{Z}^{2} \mathrm{pq} / \mathrm{d}^{2}$. Considering $\mathrm{Z}$ as 1.96 ; $\mathrm{p}$ as $0.86 .{ }^{5} \mathrm{q}$ as (1-p) and setting $\mathrm{d}$ at 0.05 , sample size of 176.8 was obtained. Considering $5 \%$ as non-response rate, the final sample size of 186 was set.

Data collection was done by observational method using WHO hand hygiene guidelines. Before collecting data, all the participants were informed in detail about the study and written informed consent was obtained. Confidentiality of the response of all the participants was maintained. The collected data were entered in MS Excel and exported to the Statistical Package for Social Sciences (SPSS) version 25 for analysis.

\section{Result:}

A total of 186 participants were enrolled out of which 5 declined to participate, so we collected data from 181 participants. There were $138(76.2 \%)$ female and $43(23.8 \%)$ male participants. The median age of the participants was 27 (range 17-58 years). The highest number of participants were nurses followed by doctors as shown in Table 1. Out of 181 participants, $72(39.8 \%)$ were in the job for less than 20 months and $152(85.1 \%)$ had prior training about infection prevention and control.

Table 1: Participants in the study:

\begin{tabular}{lr} 
Job of the participants & Number (Percentage) \\
\hline Ambulance driver & $7(3.9)$ \\
Security Guard & $6(3.3)$ \\
Maintenance staff & $7(3.9)$ \\
House keeping staff & $16(8.8)$ \\
Nurse & $89(49.2)$ \\
Doctor & $33(18.2)$ \\
Administration staff & $21(11.6)$ \\
Health Assistant & $2(1.1)$ \\
\hline
\end{tabular}

Pre and post intervention checklist were divided into 11 questions as shown in the Table 2.

Table-2: Comparison between pre and post-intervention adherence to steps of hand washing:

\begin{tabular}{llcc}
\hline No. & Steps in the checklist & Pre-intervention & Post-intervention \\
\hline 1 & Remove hand ornaments from hands and fingers if applicable & $114(63 \%)$ & $127(70.2 \%)$ \\
2 & Wet hands with water & $164(90.6 \%)$ & $175(96.7 \%)$ \\
3 & Apply enough soap to cover all hand surfaces & $128(70.7 \%)$ & $149(82.3 \%)$ \\
4 & Rub hands palm to palm & $169(93.4 \%)$ & $175(96.7 \%)$ \\
5 & Right palm over left dorsum with interlaced fingers and vice versa & $122(67.4 \%)$ & $156(86.2 \%)$ \\
6 & Palm to palm with fingers interlaced & $78(43.1 \%)$ & $116(64.1 \%)$ \\
7 & Back of fingers to opposing palm with fingers interlaced & $46(25.4 \%)$ & $99(54.7 \%)$ \\
8 & Rotating rubbing of thumb clasped in palm & $100(55.2 \%)$ & $127(70.2 \%)$ \\
9 & Rotational rubbing, backwards and forwards with clasped fingers of right & & $107(59.1 \%)$ \\
10 & hand in left palm and vice versa & $71(39.2 \%)$ & $179(98.9 \%)$ \\
11 & Pat dry thoroughly with a single use paper towel & $180(99.4 \%)$ & $179(98.9 \%)$ \\
\hline
\end{tabular}


Bangladesh Crit Care J March 2021; 9 (1): 12-15

According to competency assessment of hand hygiene, all 11 steps were summed up and categorized into good and poor hand washing on the basis of median score, which was 8 for pre intervention and 9 for post intervention. This shows that there was an overall improvement in the practice of hand washing post intervention.

As shown in Table 3, there was no observational significant difference in practice of hand washing and age of participants before intervention. But was found to have significant differences post-intervention $(\mathrm{p}=0.03)$. Regarding gender, post-intervention hand hygiene practice were found to be more significant in male than in female $(p<0.0001)$. Regarding job position, doctors and nurses had better practice regarding hand hygiene in comparison to other participants. In this study, work experience of participants was not found to be significantly associated with the practice of hand hygiene. Regarding prior training related to infection prevention and control, those who had prior training were found to have significant differences between practice of hand hygiene post-intervention.

Table 3: Hand hygiene behaviors of health care workers:

\begin{tabular}{|c|c|c|c|c|c|c|}
\hline \multirow[t]{2}{*}{ Variables } & \multicolumn{2}{|c|}{$\begin{array}{l}\text { Hand hygiene } \\
\text { pre-intervention }\end{array}$} & \multirow[t]{2}{*}{ P-value } & \multicolumn{2}{|c|}{$\begin{array}{c}\text { Hand hygiene } \\
\text { post-intervention }\end{array}$} & \multirow[t]{2}{*}{ P-value } \\
\hline & Correct & Incorrect & & Correct & Incorrect & \\
\hline \multicolumn{7}{|l|}{ Age (years) } \\
\hline$\leq 25$ & 44 & 32 & 0.310 & 53 & 23 & 0.035 \\
\hline $26-35$ & 37 & 30 & & 48 & 19 & \\
\hline $36-45$ & 11 & 16 & & 13 & 15 & \\
\hline$>45$ & 4 & 6 & & 4 & 6 & \\
\hline \multicolumn{7}{|l|}{ Gender } \\
\hline Female & 79 & 59 & 0.09 & 93 & 45 & $<0.0001$ \\
\hline Male & 17 & 26 & & 25 & 18 & \\
\hline \multicolumn{7}{|l|}{ Job Position } \\
\hline Ambulance driver & 2 & 5 & 0.004 & 3 & 4 & 0.01 \\
\hline Security guards & 1 & 5 & & 1 & 5 & \\
\hline Technician & 3 & 4 & & 3 & 4 & \\
\hline Housekeeping & 5 & 14 & & 5 & 11 & \\
\hline Nurses & 59 & 30 & & 62 & 27 & \\
\hline Doctors & 21 & 12 & & 31 & 2 & \\
\hline Administration & 5 & 16 & & 11 & 10 & \\
\hline Health assistant & 0 & 2 & & 2 & 0 & \\
\hline \multicolumn{7}{|c|}{ Work Experience (months) } \\
\hline$\leq 20$ & 38 & 34 & 0.558 & 48 & 24 & 0.20 \\
\hline $21-40$ & 27 & 17 & & 33 & 11 & \\
\hline $41-60$ & 8 & 11 & & 13 & 6 & \\
\hline $61-80$ & 2 & 4 & & 4 & 2 & \\
\hline$>80$ & 21 & 19 & & 20 & 20 & \\
\hline \multicolumn{7}{|c|}{ Prior training regarding infection prevention and control } \\
\hline Yes & 79 & 75 & 0.183 & 99 & 55 & $<0.0001$ \\
\hline No & 17 & 10 & & 19 & 8 & \\
\hline
\end{tabular}




\section{Discussion:}

This study was designed to evaluate hand hygiene skills of the health care workers and the effect of training and educational intervention on it.

In a study by Kukanich et al, conducted in two outpatient health care clinics, result was poor at baseline (11\% and $21 \%)$ but improved significantly after intervention (36\% and 54\%) which resembles our result. ${ }^{6}$ Similar study by Huang et al, showed significant improvement in the nurses' knowledge, practice and behavior regarding universal precaution after educational intervention which is similar to the result of our study. ${ }^{7}$

In the present study, both pre and post-tests showed that doctors and nurses had better hand hygiene practice than other participants. Possibilities might be due to the better academic background and motivation on infection control issues by the experienced health personnel in the hospitals. Similarly, in a study done in Saudi Arabia, adherence to hand hygiene was seen in $70 \%$ medical students, $18.8 \%$ of nurses and $9.1 \%$ of senior medical staff. ${ }^{8}$

Self-assessment questionnaires have been shown to be effective methods for the evaluation of hand hygiene among health care workers but they are liable to overestimate compliance of the respondents. ${ }^{9}$ From the study done in Swedish hospital, a single lecture on hand hygiene had significant and sustained effect in enhancing hand hygiene compliance. ${ }^{10}$ In congruence, many other studies have demonstrated similar effectiveness after the awareness workshop in enhancing the hand hygiene. ${ }^{11,12} \mathrm{We}$ found similar resemblance in this study.

In this study, particular attention was given during data collection to maintain the confidentiality of the respondents. A similar study was done in Uganda, where the professional identity of the participants was kept confidential, which was a motivating factor for the health care workers. ${ }^{13}$

In the current study, the participants who had prior training on infection control performed better after intervention. Similar findings were reported from a study done among nursing students in Uttar Pradesh, India where majority (90\%) had received formal training in the previous 3 years. ${ }^{14}$

The result of the study is promising to enhance the hand hygiene practices among the health care workers. Our study highlights the importance of interventions like training sessions and workshops to improve hand hygiene practices.

The lack of a control group limits the generalizability of the findings of our study. The lack of control group may limit the rigor of the study given the fact that the participants presented the same evaluation in the pre and post-test. The long-term effectiveness of intervention could not be assessed due to lack of follow up in this study. In a similar study by Sjoberg M. et al, there was a $21 \%$ increase in the consumption of hand disinfectant for hand washing after lecture on basic hygiene routines to all employees on the ward even at 9 months follow up. ${ }^{10}$ The higher compliance in the follow up justifies the improvement in the hand hygiene. Also, this study only focused on the techniques of hand washing but did not evaluate other factors such as time spent or the products used for hand hygiene.

\section{Conclusion:}

It can be concluded that training and educational interventions are the effective tools to improve hand hygiene skills of the health care workers. Performing such interventions at regular intervals can be helpful.

\section{References:}

1. World Health Organization. Evidence of hand hygiene as the building block for infection prevention and control: an extract from the systematic literature reviews undertaken as the background for the WHO guidelines on core components of infection prevention and control programmes at the national and acute health care facility level. World Health Organization; 2017.

2. World Health Organization (WHO). World Health Organization campaigns on clean hands. Geneva: WHO; 2020.

3. Allegranzi B, Gayet-Ageron A, Damani N, Bengaly L, McLaws ML, Moro ML et al. Global implementation of WHO's multimodal strategy for improvement of hand hygiene: a quasi-experimental study. Lancet Infect Dis.2013;13:843-51.

4. Safety WP. World Health Organization. WHO guidelines on hand hygiene in health care: a summary. World Health Organization; 2009.

5. Park HY, Kim SK, Lim YJ, Kwak SH, Hong MJ, Mun HM et al. Assessment of the appropriateness of hand surface coverage for health care workers according to World Health Organization hand hygiene guidelines. Am J Infect Control. 2014;42:559-61.

6. Kukanich KS, Kaur R, Freeman LC, Powell DA. Evaluation of a hand hygiene campaign in outpatient health care clinics. Am J Nurs.2013;113:36-42.

7. Huang J, Jiang D, Wang X, Liu Y, Fennie K, Burgess $J$ et al. Changing knowledge, behavior, and practice related to universal precautions among hospital nurses in China. J Contin Educ Nurs.2002;33:217-24

8. Basurrah MM, Madani TA. Handwashing and gloving practice among health care workers in medical and surgical wards in a tertiary care centre in Riyadh, Saudi Arabia. Scand J Infect Dis. 2006;38:620-4.

9. Moret L, Tequi B, Lombrail P. Should self-assessment methods be used to measure compliance with handwashing recommendations? A study carried out in a French university hospital. Am J Infect Control.2004;32:384-90.

10. Sjoberg S, Eriksson M. Hand disinfectant practice: the impact of an education intervention. Open Nurs J.2010;4:20-4.

11. Abdalrahman I, Shamat S, Mamoun S, Abdelraheem R, Salah E, Elkhalifa $\mathrm{M}$ et al. Educational sessions may not be enough to improve knowledge about hand hygiene: Assessing the knowledge about hand hygiene of health workers before and after an educational workshop in Sudan. F1000Research. 2018;7:449.

12. Hong SY,Jang HJ. The effect of a hand washing education program for pre-practicum nursing students. Int J Software Engineering Applications.2016;10:161-70.

13. Kyaddondo D, Whyte SR. Working in a decentralized system: a threat to health workers' respect and survival in Uganda. Int J Health Plann Manage. 2003;18:329-42.

14. Mahmood S, Verma R, Khan MB. Hand hygiene practices among nursing students: importance of improving current training programs. Int J Community Med Public Health. 2015;2:466-71. 